\title{
Efficacy of 3 anthelmintics in communally grazed sheep as reflected by faecal egg count reduction tests in a semi-arid area of South Africa
}

\author{
F R Bakunzi
}

\begin{abstract}
A survey was conducted on the occurrence of anthelmintic resistance of nematodes in communally grazed sheep in a semi-arid area near Mafikeng, South Africa, from January to March 2006. In the herds belonging to twelve smallholder sheep farmers, the efficacies of albendazole, levamisole and closantel were tested by faecal egg count reduction tests where $80 \%$ efficacy was considered the cut off for anthelmintic resistance. The results of the faecal egg count reduction tests showed more than $80 \%$ efficacy with all the drugs used in most cases, but there were notable exceptions. In 1 case, closantel had an efficacy of $72 \%$, albendazole had an efficacy of $68 \%$ and levamisole showed efficacies of $58 \%, 60 \%$ and $75 \%$ respectively on 4 farms. The occurrence of anthelmintic resistance in this farming sector is of concern and steps should be taken to prevent its further spread and development to avoid a situation developing as on numerous commercial sheep farms in South Africa where resistance is common.
\end{abstract}

Key words: albendazole, closantel, communal grazing, drug resistance, levamisole, nematodes, sheep, South Africa.

Bakunzi F R Efficacy of 3 anthelmintics in communally grazed sheep as reflected by faecal egg count reduction tests in a semi-arid area of South Africa. Journal of the South African Veterinary Association (2008) 79(1): 54-55 (En.). Department of Animal Health, North West University, PO Box 1372, Mafikeng, 2745 South Africa

Anthelmintic resistance of nematodes in small stock is seen worldwide and has become an important factor in the management of trichostrongylosis in the tropics $^{2,4,12}$. In France, $85 \%$ of goat dairy farms harbour benzimidazole-resistant nematodes ${ }^{5}$. In South Africa, anthelmintic resistance has become a major problem in commercial sheep farming. One study reporting on 3 surveys indicated that more than $90 \%$ of the farms harboured Haemonchus strains that were resistant to at least 1 of the 4 anthelmintics tested and that between 60 and $78 \%$ of these strains were resistant to 3 anthelmintic groups ${ }^{12,14}$. Similar anthelmintic resistance problems have been reported on commercial sheep farms in Zimbabwe $e^{4}$ and many other parts of the world ${ }^{1,3,6-9}$ The available literature indicates little about the degree of resistance of nematodes to the commonly used anthelmintics in communally grazed small ruminants in South Africa with the exception of that reported in the resource-limited communal grazing area of Lebowa ${ }^{12}$ and Mafikeng ${ }^{2,11}$ and on a farm at Rust de Winter ${ }^{17}$. Therefore, the present survey was undertaken to ascertain the

a'Department of Animal Health, North-West University, PO Box 1372, Mafikeng, 2745 South Africa

E-mail: bakunzif@uniwest.ac.za

Received: May 2007. Accepted: February 2008. occurrence of anthelmintic resistance of communally grazed sheep against 3 commonly used groups of anthelmintics. This study was conducted within a radius of approximately $60 \mathrm{~km}$ of Mafikeng City, North West province, South Africa, from January to March 2006.

Twelve smallholder sheep farmers, each rearing 40 or more sheep of mixed breed ('village sheep') on communally managed rangelands, were included in this study. The predominant traits displayed by the sheep were those of the Dorper and Merino. These sheep also grazed freely, together with goats and cattle. During the 1 st visit to the farmers, 4 groups of 10 sheep each, of different age and sex, were selected at random. All animals were ear-tagged, weighed and faecal samples were taken from each sheep rectally and transported in an ice-cooled box and stored in the laboratory at $4{ }^{\circ} \mathrm{C}$ before analysis. One group was treated with albendazole (Prodose Green, Virbac Animal Health ) as an oral drench at a dose of $7.5 \mathrm{mg} / \mathrm{kg}$ live mass. The $2 \mathrm{nd}$ group was treated with levamisole (Tramisol, Afrivet) as an oral drench at a dose of $7.5 \mathrm{mg} / \mathrm{kg}$ live mass. The $3 \mathrm{rd}$ group was treated with closantel (Prodose Yellow, Virbac Animal Health), as an oral drench at a dose of $5 \mathrm{mg} / \mathrm{kg}$ live mass. The 4th group was not treated and served as a control. Fourteen days after the 1st visit, each farm was revisited and faecal samples were taken from the same 40 marked sheep. Individual faecal samples collected during both visits were examined for nematode eggs using a modification of the McMaster technique ${ }^{10}$ on the day of collecting the samples. The arithmetic mean of the individual counts before and after treatment was calculated for each group. The faecal egg count reduction (FECR) percentage was calculated according to the equation ${ }^{4}$ :

FECR $\%=\left(1-T_{2} / T_{1} \times 20 C_{1} / C_{2}\right) \times 100$,

where $T$ and $C$ are the arithmetic means of the egg counts of the treated and control groups, respectively. The subscripts 1 and 2 designate the counts before and after treatment, respectively. In this study, the threshold for efficacy was considered to be $80 \%$, according to Kettle et al. ${ }^{7}$ as the threshold at which an anthelmintic was considered effective by Boersema and Pandey ${ }^{4}$ was not stated. Pooled faecal samples using the same amount of faeces from all the 40 treated animals after the 1 st visit were incubated at $25^{\circ} \mathrm{C}$ in a Labotec incubator for 5 days and the 3rd-stage nematode larvae $\left(l_{3}\right)$ were harvested to differentiate which trichostrongylid genus was most dominant, using the method developed by Van Wyk et al. ${ }^{16}$. Table 1 shows the anthelmintic efficacy, based on faecal egg count reduction (FECR \%) of albendazole, closantel and levamisole of all the 12 farmers included in the study. The efficacy percentage shown in Table 1 based on FECR for albendazole varied from $68 \%$ to $96 \%$. Levamisole based on egg counts showed an efficacy from $58 \%$ to $100 \%$ while closantel varied from $72 \%$ to $100 \%$. On examination of the $l_{3}$, the most prevalent genus was Haemonchus spp., followed by Oesophagostomum spp. and Trichostrongylus spp. Similar prevalence has been reported in communally grazed goats probably due to free grazing of sheep and goats on communal rangelands ${ }^{2}$. In summer rainfall areas, Haemonchus has also been reported to be the most prevalent genus $^{13}$. 
Table 1: Anthelmintic efficacy (\%) in sheep on 12 farms in the Mafikeng area.

\begin{tabular}{lrrrrrrrrrrrr} 
Drug & \multicolumn{10}{c}{ Farm } \\
\cline { 2 - 12 } & \multicolumn{1}{r}{} & $\mathbf{2}$ & $\mathbf{3}$ & $\mathbf{4}$ & $\mathbf{5}$ & $\mathbf{6}$ & $\mathbf{7}$ & $\mathbf{8}$ & $\mathbf{9}$ & $\mathbf{1 0}$ & $\mathbf{1 1}$ & $\mathbf{1 2}$ \\
\hline ABZ & 95 & 96 & 68 & 93 & 86 & 82 & 92 & 88 & 95 & 81 & 93 & 96 \\
LV & 58 & 100 & 58 & 100 & 95 & 100 & 60 & 91 & 75 & 89 & 85 & 84 \\
CLO & 100 & 94 & 72 & 100 & 85 & 88 & 92 & 99 & 89 & 91 & 100 & 87 \\
\hline
\end{tabular}

Key: $\mathrm{ABZ}=$ Albendazole, $\mathrm{LV}=$ Levamisole, $\mathrm{CLO}=$ Closantel.

The efficacies of drugs used in the present study were generally above $80 \%$, suggesting that the level of anthelmintic resistance may not be as high as on commercial sheep farms in southern Africa $^{12}$. The reasons for low resistance in communally grazed sheep is probably due to infrequent dosing by resourcepoor farmers. There may therefore still be the prospect of slowing down the development of severe anthelmintic resistance against the commonly used groups of anthelmintics in communally grazed sheep in this region. However, on farm no. 3 the efficacies of albendazole and closantel were $68 \%$ and $72 \%$, respectively while levamisole showed efficacies of $58 \%, 60 \%$ and $75 \%$ on farms $1,3,7$ and 9 , respectively (Table 1 ). This indicated presence of resistant nematode populations on those 4 farms. The anthelmintic resistance noticed in this survey in communally grazed sheep may be due to underdosing as a result of limited financial resources ${ }^{15}$. This was especially so on farm no. 3 where it was mentioned on investigation that the animals were dosed with small amounts to both sick and healthy animals due to lack of money. On this farm the nematodes displayed resistance to all 3 drugs used in the study. The anthelmintic efficacy indicated on farm no. 3 to closantel might have been higher than $72 \%$. Closantel has high efficacy only against blood-sucking parasites like Haemonchus spp. and hookworms, and not against Oesophagostomum spp. and Trichostrongylus spp. which were observed in the pre-treatment cultures. In addition to underdosing, emerging farmers often buy animals at auctions supplied by commercial farms on which anthelmintic resistance may be present, and in this way resistant nematode populations or strains may be disseminated. Levamisole displayed nematode resistant strains in 4 of
12 farms as compared with either albendazole or closantel which showed only 1 of 12 farms. Levamisole is the cheapest broad-spectrum anthelmintic in the Mafikeng region and because of this it is affordable by most communal farmers who frequently use it and this probably selects for resistant nematode strains ${ }^{12}$, which might have been the case in this study. Similar levamisole resistance was reported on 2 of 10 communal goat farms ${ }^{2}$.

The occurrence of anthelmintic resistance in the smallholder farming sector is a cause for concern. Steps should therefore be taken to prevent its further spread and to avoid the development of a situation as on commercial sheep farms in South Africa where resistance is common ${ }^{13}$.

\section{ACKNOWLEDGEMENTS}

The author thanks the North West University Research committee for financial support, the communal farmers for their cooperation and the Animal Health Technicians for their assistance in faecal sample collection.

\section{REFERENCES}

1. Abdul J, Zafar I, Dominique K, Muhammad G, Khan M.N, Afaq M 2006 Anthelmintic resistance: The state of play revisited. Life Sciences 79: 2413-2431

2. Bakunzi F R 2003 Anthelmintic resistance of nematodes in communally grazed goats in a semi-arid area of South Africa. Journal of the South African Veterinary Association 74(3): 82-83

3. Besier R B, Love S C J 2003 Anthelmintic resistance in sheep nematodes in Australia: the need for new approaches. Australian Journal of Experimental Agriculture 43: 13831391

4. Boersema J H, Pandey V S 1997 Anthelmintic resistance of trichostrongylids in sheep in the highveld of Zimbabwe. Veterinary Parasitology 68: 383-388

5. Cabaret J, 2002. How do we deal with anthelmintic resistance of herbivore hel- minths? In: Proceedings of the 27th World Veterinary Congress, 25-29 September, Tunis: 294-295

6. Chandrawathani P, Yusoff N, Wan L C, Ham A, Waller P J 2004 Total anthelmintic failure to control nematode parasites of small ruminants on government breeding farms in Sabah East Malaysia. Veterinary Research Communications 28: 1-11

7. Kettle P R, Vlassoff A, Reid T C, Horton C T 1983 A survey of nematode control measures used by milking goat farmers and of anthelmintic resistance on their farms. New Zealand Veterinary Journal 31: 139-143

8. Maingi N, 1991 Resistance to thiabendazole, fenbendazole and levamisole in Haemonchus and Trichostrongylus species in sheep on a Kenyan farm. Veterinary Parasitology 39: 285-291

9. Ndamukong K J N, Sewell M M H, 1992 Resistance to benzimidazole anthelmintics by trichostrongyles in sheep and goats in North West Cameroon. Veterinary Parasitology 41: 335-339

10. Reinecke R K, 1983 Veterinary helminthology. Butterworths, Durban/Pretoria

11. Tsholofero B M, Bakunzi F R 2002 Anthelmintic resistance in communally grazed sheep in Northwest Province, South Africa. In Donkin E F (ed.) Small ruminant production in southern Africa. Proceedings of the annual symposium of the developing Animal Agriculture Interest Group of the South African Society for Animal Science, Jan Kempdorp, September/October 2002: 77-81

12. Van Wyk J A, Stenson M O, Van der Merwe J S, Vorster R J, Viljoen P G 1999 Anthelmintic resistance in South Africa: surveys indicate an extremely serious situation in sheep and goat farming. Onderstepoort Journal of Veterinary Research 66(4): 273-284

13. Van Wyk J A, 1990 A review of chemical methods available for the control of gastrointestinal nematodes of sheep and cattle. Journal of the South African Veterinary Association 61: 136-140

14. Van Wyk J A, Malan F S, Gerber H M, Alves R M R 1989 The problem of escalating resistance of Haemonchus contortus to the modern anthelmintics in South Africa. Onderstepoort Journal of Veterinary Research 56: 41-49

15. Van Wyk J A, Hoste H, Kaplan R M, Besier R B 2006. Targeted selective treatment for worm management - How do we sell rational programs to farmers? Veterinary Parasitology 139: 336-346

16. Van Wyk J A, Cabaret J, Michael L M 2004 Morphological identification of nematode larvae of small ruminants and cattle simplified. Veterinary Parasitology 119: 277-306

17. Vatta A F, Letty B A, van der Linde M J, van Wijk E F, Hansen J W, Krecek R C 2001 Testing for clinical anaemia caused by Haemonchus spp. in goats farmed under resource-poor conditions in South Africa using an eye colour chart developed for sheep. Veterinary Parasitology 99: 1-14 